\author{
Revista Brasileira de Educação do Campo \\ Brazilian Journal of Rural Education \\ ARTIGO/ARTICLE/ARTÍCULO \\ DOI: $\underline{\text { http://dx.doi.org/10.20873/uft.rbec.e13296 }}$
}

\title{
Avaliação, monitoramento e acompanhamento do processo formativo na RCT: aspectos teórico-práticos e operacionais
}

Kátia Cristina Custódio Ferreira Brito ${ }^{1}$, (iD) Adaires Rodrigues de Sousa ${ }^{2}$, iD Roberto Francisco de Carvalho ${ }^{3}$

1,3 Universidade Federal do Tocantins - UFT. Campus de Palmas - Programa de Pós-Graduação em Educação - Avenida NS 15, 109 Norte - Plano Diretor Norte - Palmas - TO. Brasil. ${ }^{2}$ Faculdade de Psicologia e Ciências da Educação da Universidade de Coimbra, Portugal.

Autor para correspondência/Author for correspondence: katiacristina@uft.edu.br

RESUMO. O artigo em pauta aborda temática referente a avaliação, monitoramento e acompanhamento da Rede ColaborAção Tocantins (RCT), no contexto do período pandêmico. A presente reflexão tem o objetivo de problematizar a concepção instrumental da educação e da avaliação por meio de reflexão teórico-filosófica, que entende a educação como práxis social, calcada nos princípios da gestão democrática e da formação substantiva. O estudo que originou esse texto foi realizado na perspectiva crítico-dialética, partindo da realidade empírica compreendida como realidade complexa, contraditória e mediatizada por múltiplos determinantes. O estudo proporcionou - como resultado teórico-prático - a explicitação dos fundamentos filosóficos, políticos e metodológicos da avaliação, monitoramento e acompanhamento nas perspectivas instrumental e substantiva, bem como possibilitou a composição de um conjunto de critérios e procedimentos aplicáveis à formação no âmbito da gestão da educação municipal. A discussão contempla, além de aspectos teórico-práticos da gestão, da avaliação, do monitoramento e do acompanhamento da RCT, aspectos práticos operacionais do processo formativo.

Palavras-chave: educação no Tocantins, rede colaborAção Tocantins (RCT), avaliação, monitoramento e acompanhamento da educação municipal, aspectos teóricos e práticos. 


\title{
Evaluation monitoring and accompaniment of the training process in RTC: theoretical-practical and operational aspects
}

\begin{abstract}
The article at stake approaches thematic related to the evaluation, monitoring and accompaniment of the Rede ColaborAção Tocantins (RCT) developed in the pandemic period. The present reflection has objective to problematize the instrumental conception of the education and the evaluation by means of theoretician-philosophical reflection, which understands the education as social práxis, based on principles of the democratic management and the substantive formation. The study which originated this text was carried through in the perspective critical-dialectic, starting from the empirical reality understood as complex reality, contradictory and mediatized by multiples determinative. The study provided - as a theoreticalpractical result - the explanation of the philosophical, political and methodological foundations of evaluation, monitoring and follow-up in the instrumental and substantive perspectives, as well as this enabled the composition of a set of criteria and procedures applicable to training in municipal education management. The discussion includes, in addition to the theoretical and practical aspects of management, evaluation, monitoring and accompaniment, the practical operational aspects of the training process.
\end{abstract}

Keywords: education in the Tocantins, rede colaborAção Tocantins (RCT), evaluation monitoring and accompaniment of municipal education, theoretical and practical aspects. 


\section{Evaluación, monitoreo y acompañamiento del proceso formativo en la RCT: aspectos teórico-prácticos y operacionales}

RESUMEN. El artículo aborda la evaluación, monitoreo y acompañamiento de la Rede ColaborAção Tocantins (RCT) desarrollada en el período pandémico. Tiene por objetivo problematizar la concepción instrumental de la educación y de la evaluación mediante reflexión teórico-filosófica, que comprende la educación como praxis social, calcada en los principios de la gestión democrática y de la formación sustantiva. El estudio que origino ese texto fue realizado en la perspectiva criticodialéctica, partiendo de la realidad empírica comprendida como realidad compleja, contradictoria y mediatizada por múltiplos determinantes. El estudio ha permitido, como resultado teórico y práctico, el esclarecimiento de los fundamentos filosóficos, políticos y metodológicos de la evaluación, monitoreo y seguimiento en las perspectivas instrumental y sustantiva, así como posibilitó la composición de un conjunto de criterios y procedimientos aplicables a la formación en el ámbito de la gestión de la educación municipal. Además de los aspectos teóricos-prácticos de la gestión, contempla la evaluación, monitoreo y acompañamiento, los aspectos prácticos operacionales del proceso formativo.

Palabras clave: educación en Tocantins, rede colaborAção Tocantins (RCT), evaluación, monitoreo y acompañamiento de la educación municipal, aspectos teóricos y prácticos. 


\section{Introdução}

A temática de avaliação, monitoramento e acompanhamento da Rede ColaborAção Tocantins (RCT) - com relação às ações desenvolvidas no período pandêmico - constitui o centro das preocupações do presente texto. Historicamente, a discussão sobre a avaliação, incluindo o monitoramento e o acompanhamento, tem priorizado a perspectiva instrumentalizada de educação, com a finalidade de estabelecer parâmetros de produção e de controle nas relações de trabalho diversas.

A discussão em pauta tem o objetivo geral de problematizar a concepção instrumental de educação, gestão e avaliação por meio de reflexão teóricofilosófica que entende a educação como práxis social calcada nos princípios da gestão democrática e da formação substantiva. Nessa linha de pensamento, o prisma que sustenta a nossa argumentação fundamenta-se no entendimento omnilateral de educação como prática educativa historicamente situada na sociedade capitalista. Nesse entendimento, o ato de planejar, praticar e avaliar é parte constitutiva e constituinte do processo educativo e precisa ser compreendido na condição de totalidade das relações sociais contraditórias em constante movimento.
Subsumido à compreensão anteriormente aventada, o presente estudo - de base bibliográfica e empíricodocumental - foi realizado na perspectiva crítico-dialética, partindo da realidade empírica avaliativa, realizada no âmbito da RCT, compreendida em sua complexidade, contraditória e mediatizada por múltiplos determinantes econômico-materiais, institucionais, políticos, culturais e ideológicos.

Após a realização da pesquisa, a exposição lógica e histórica dos resultados contempla, além de uma discussão sobre os aspectos teórico-práticos da gestão, da avaliação, do monitoramento e do acompanhamento, também os aspectos práticos e operacionais do processo formativo realizado pela RCT junto às redes e aos sistemas de ensino/educação do Tocantins, no período pandêmico da Covid-19.

\section{Aspectos teórico-práticos da gestão, da avaliação, do monitoramento e do acompanhamento da RCT}

Avaliar, monitorar e acompanhar não são processos simples, pois envolvem aspectos objetivos e subjetivos, desde a construção do instrumento, seguido do acompanhamento do processo até o resultado atingido mediante objetivos estabelecidos. É preciso clareza, coerência 
e compromisso dos envolvidos no processo avaliativo para a realização de uma avaliação satisfatória, justa e participativa. Embora a avaliação não seja fácil, conforme Dias Sobrinho (2003),

... ela hoje se estende aos domínios de todas as produções sociais, das políticas públicas, especialmente das educacionais. Inscreve-se no terreno das reformas, inovações, currículos, programas e projetos e exerce um papel de real importância na configuração dos modelos das instituições, organizações e sistemas. Em outras palavras, a avaliação vem ganhando cada vez mais densidade política e crescentemente é utilizada como instrumento de poder e estratégia do governo (Dias Sobrinho, 2003, p. 9).

A avaliação, o monitoramento e o acompanhamento inerentes a determinado processo educacional relacionam-se, em grande medida, à concepção de educação, à forma de gestão em geral e ao ideário de regulação que adotamos. Nesse sentido, atinente à avaliação do processo formativo no âmbito da Rede ColaborAção Tocantins (RCT), entendendo a educação como uma prática social situada no contexto atual da pandemia causada pela Covid-19 e realizada na perspectiva da gestão democrática, este estudo tem como referência teórico-metodológica a tradição interacionista de administração das instituições sociais.

A esse respeito, destacamos que duas tradições da administração em geral podem ser visualizadas: a funcionalista, enraizada nas teorias positivista e evolucionista; e a interacionista, que procura mediar reflexivamente as diferenças sociais numa perspectiva de diálogo (Carvalho, 2011). Na gestão dialógica, a mediação ocorre de forma dialética e consiste em nova maneira de planejar, executar e avaliar o processo educativo, pois nela são privilegiados o diálogo e a discussão, com ênfase nos princípios da totalidade, contradição, práxis e transformação do sistema educacional.

Analisando o contexto educacional brasileiro, Carvalho (2011, p. 84) apresenta uma tensão entre duas concepções de gestão/regulação dos processos educativos:

... a regulatório-regulamentatória de
natureza estratégico-empresarial,
fundamentada na tradição
funcionalista, para a qual o controle
burocrático e a busca por uma
produção eficiente de perspectiva
economicista são características
intrínsecas, e a regulatório-
emancipatória de natureza
democrático-participativa,
fundamentada na tradição
interacionista, perspectiva que
prima pela participação efetiva dos
agentes que compõem os
segmentos de determinada
instituição social.

A partir do exposto, esclarecemos que a palavra regulação, como prefixo, também se aplica à perspectiva emancipatória, que não exclui a necessidade de regulação. Dessa forma, 
entendemos que quanto mais

preponderante for a perspectiva de

regulação com enfoque regulamentatório

de natureza estratégico-empresarial em um

processo de gestão e de avaliação

educacional, mais limitada será a interação

efetiva dos sujeitos que compõem tal

prática educativa. Os processos de regulação, em quaisquer das perspectivas de gestão e avaliação aventadas, são explicitados por Cristina Contera (2002, p. 132-136), que apresenta argumentos de natureza filosófica, política e metodológica e os caracteriza conforme o quadro seguinte:

Quadro 1 - Gestão/avaliação de processo educacional e escolar.

PERSPECTIVAS: Estratégico-empresarial e Democrático-participativa

\begin{tabular}{|l|}
\hline Gestão/Avaliação estratégico-empresarial \\
\hline - Do ponto de vista filosófico, esse modelo \\
se orienta por uma racionalidade instrumental em \\
que predomina um interesse técnico. Os juízos \\
objetivos de eficácia instrumental se baseiam \\
inteiramente na evidência concreta do grau em \\
que determinado curso de ação conduz às \\
consequências pretendidas (ou aos objetivos \\
pretendidos).
\end{tabular}

- Do ponto de vista político, é claramente um modelo cuja intencionalidade explícita é que as instituições, como escolas e universidades públicas, 'prestem contas' (accountability) do uso do orçamento concedido pelo Estado ... uma nova forma de Estado, o Estado avaliador, [que se pauta] nos valores de competitividade, esforço individual e produtividade própria do mercado ... O ensino é um instrumento técnico a serviço de objetivos políticos, definidos prioritariamente por exigências econômicas externas, cuja determinação escapa precisamente a quem participa da vida cotidiana das instituições educativas.

- Do ponto de vista metodológico, o modelo se sustenta em enfoque predominantemente quantitativo, já que se parte de uma análise custo-benefício, de insumos resultados e se desconhecem ou simplesmente ignoram os processos. Enfatiza-se a busca de indicadores de rendimento, fixação de padrões, provas e testes com um objetivo de controle (Contera, 2002, p. 132-134).

Fonte: elaboração dos autores com base em Contera (2002); Carvalho (2011).

\section{Gestão/Avaliação democrático-participativa}

- Do ponto de vista filosófico, critica-se a racionalidade instrumental como sendo incapaz de argumentar sobre a qualidade valorativa dos fins com os quais se relaciona. Recupera-se o interesse emancipatório concebido não exclusivamente, como o interesse cognoscitivo prático da ciência, como o interesse emancipador por meio da autorreflexão, se não como um fim último, um valor e um processo que aponta como ideal regulativo, como possibilidade e como antecipação à associação de indivíduos autodeterminados de forma racional e justa.

- Do ponto de vista político, diferentemente do modelo de regulação, o modelo democrático orienta-se para a defesa da autonomia e para a capacidade de autogoverno das instituições de educação ... O processo se sustenta em valores interno e externo; interesse pela produção do conhecimento e sua distribuição; pertinência social do conhecimento, equidade e transparência de suas decisões, participação e autonomia institucional e docente.

- Do ponto de vista metodológico, não se observam exclusivamente os resultados ... importam os insumos e os produtos, mas sobretudo a análise dos processos. Para isso se substituem os indicadores de rendimento pelos de qualidade e se opta pela seleção de procedimentos e técnicas que combinam o quantitativo com o qualitativo (Contera, 2002, p. 134-136).
Destacamos, a partir da leitura do Quadro 1, que a perspectiva de regulação estratégico-empresarial se fundamenta nos valores referentes à competitividade, ao esforço individual e à produtividade, que prevalecem sobre a perspectiva de compartilhamento do poder em uma determinada coletividade. Em contraste ou 
contradição com a perspectiva da regulação, mas não de forma mecanicista, a perspectiva da emancipação ou democrática constitui-se, nesse sentido, na concepção de educação, gestão e avaliação, na qual a dimensão política e, portanto, a valorização dos sujeitos em processo educativo têm maior evidência e importância.

Ressaltamos que as perspectivas de regulação estratégico-empresarial e democrático-participativa fazem parte de uma mesma e contraditória totalidade social, portanto, representam projetos de educação em disputa. O esforço pela caracterização dessas duas perspectivas de gestão e avaliação, nesse sentido, tem uma função didática, com a finalidade de explicitar a perspectiva que é tendencialmente mais propícia a uma formação de participação efetiva, diagnóstica e processual. Assim, estabelecida essa breve diferenciação, tensionada entre a perspectiva da regulação de natureza estratégico-empresarial e a da emancipação de natureza democráticoparticipativa do processo educativo e apontada essa última como mais propícia a uma gestão democrático-participativa e a uma avaliação formativa efetiva dos sujeitos que compõem dado processo educativo sistêmico ou escolar, podemos caracterizar as suas consequências formativas em geral e delinear a perspectiva avaliativa que fundamenta avaliação no âmbito da RCT.

Estamos nos referindo a duas perspectivas de gestão e avaliação da educação com encaminhamentos teóricopráticos de cunho mercantil e emancipatório, com implicações formativas alinhadas às perspectivas econômico-mercantil e políticoemancipatória (Dias Sobrinho \& Ristoff, 2002), conforme espelhamento descrito no seguinte quadro:

Quadro 2 - Implicações para o processo formativo.

\begin{tabular}{|c|c|}
\hline Perspectiva econômico-mercantil & Perspectiva político-emancipatória \\
\hline $\begin{array}{ll}\text { - } & \text { Foco na profissionalização; } \\
\text { - } & \text { Produtivismo, Imediatismo, Utilitarismo; } \\
\text { - } & \text { Conformismo com a lógica mercantil; } \\
\text { - } & \text { Formação unilateral: estreita e bárbara; } \\
& \text { Pedagogia dos resultados quantitativos. }\end{array}$ & $\begin{array}{l}\text { - Foco na formação humana; } \\
\text { - Sem foco no imediatismo e no } \\
\text { pragmatismo mercantil; } \\
\text { - Construção do conhecimento; } \\
\text { - } \quad \text { Formação omnilateral: ampla e humana; } \\
\text { - Formação de qualidade socialmente } \\
\text { referenciada. }\end{array}$ \\
\hline
\end{tabular}

Fonte: elaboração dos autores com base em Dias Sobrinho e Ristoff (2002); Carvalho (2011).

Como síntese antecipadora do recorte teórico-metodológico de avaliação (Dias
Sobrinho e Ristoff, 2002) que a RCT propõe para o processo formativo, 
afirmamos que não se pretende realizá-la: na lógica empresarial do imediatismo, do utilitarismo, do economicismo, do produtivismo; e na lógica do mercado, do conformismo dos caminhos já trilhados, da uniformidade, da avaliação somativa, do interesse preferencialmente pelo produto, do pensamento da qualidade entendida como quantidade, do sonho com o impacto na mídia e por meio do desmonte do espaço público.

Assim, por contraposição tensionada, o que propomos é uma avaliação: na lógica do sistema/rede de ensino/educação e da instituição escolar viva, capaz de ver o presente (com seus entraves e suas realizações) sem perder de vista o futuro, que pode realizar o útil sem tornar-se utilitarista, que pode ser eficiente sem cair no eficienticismo, que pode ser produtiva sem ser vitimada pelo produtivismo (Chauí, 1980); na lógica do espaço educacional (sistema/rede municipal e escolar concreto), da autonomia, da construção do conhecimento e dos saberes, do respeito às diferenças, da avaliação formativa, da valorização dos processos e da qualidade social substantiva como meta principal.

Evidentemente não estamos falando da "qualidade" que expressa competência e excelência que satisfaz os critérios da modernização da economia e do desenvolvimento social pautado pela produtividade, orientada pelos critérios do quanto a realidade educacional avaliada "produz, em quanto tempo produz e qual o custo do que produz" (Chauí, 1999, p. 3). Estamos, sim, buscando a qualidade social acerca da qual o processo avaliativo busca responder "o que se produz, como se produz, para que ou para quem se produz" (Chauí, 1999, p. 3), em contraste com uma lógica educativa que inverte a ideológica da qualidade em quantidade.

São esses os fundamentos que guiaram a elaboração dos instrumentos, a produção, organização e análise dos dados em relação ao processo avaliativo, no âmbito da RCT, acrescidos da referência à concepção de gestão democráticoparticipativa do processo educativo, conduzido na perspectiva da construção da autonomia pelos sistemas/redes de educação/ensino, incluída a priorização da participação, também, na avaliação do processo formativo.

Ressaltamos, por essa linha de entendimento, que a questão da participação merece especial atenção no sentido de que, sem ela, será difícil a consecução e concretização dos objetivos educacionais no seu sentido mais substantivo. Desse modo,

... a avaliação participativa é, então, formativa, pois, nesse caso, é também um processo de socialização 
e de democratização. Assim como o "eu" se constrói sempre em relação com o "outro", a avaliação, como processo relacional, tem também duas dimensões, que não se opõem, antes, se completam: a auto e a heteroavaliação. A autoavaliação é um autoquestionamento que passa pelo outro, nos processos de heteroavaliação, e retorna ao sujeito, enriquecida com novas aprendizagens, em um patamar diferente de experiências. Dessa forma, a autoavaliação - exercida no campo das relações interpessoais e dialógicas, portanto, combinada com as visões externas - é um importante processo de individuação e de socialização, ou seja, de constituição do sujeito humano (Dias Sobrinho, 2005, p. 29-30).

Estudiosos da educação, como Dias Sobrinho (2005), já produziram sólidos conhecimentos acerca da relação educação/participação com fortes argumentos de validade da avaliação participativa que se baseia na construção coletiva do conhecimento por uma comunidade constituída por sistemas articulados de comunicação e aprendizagem e voltada para os objetivos e valores - diversos e diversificados - da formação humana e do desenvolvimento emancipatório da sociedade. Por essa lógica, defendemos, nos processos participativos, mais que uma certeza absoluta, indiscutível, neutra, prevalecer a referência social, relativa, contextualizada e resultado das lutas e dos entendimentos possíveis em cada realidade educativa.
Ainda ancorados no supracitado autor, depreendemos que os processos que requerem a participação dos sujeitos nas práticas e relações sociais não consistem em simples balanço, não se limitam a controle, nem têm como produto uma objetividade desencarnada do corpo social em movimento e contradição. Em outras palavras, não se trata de certezas consolidadas e acabadas, mas de uma construção inacabada e indeterminada, socialmente desenvolvida, sendo, portanto, amplamente participativa e plural, em busca da compreensão dos significados e sentidos, em cujo processo social contraditório e conectado os sujeitos do processo educativo se assumem como corresponsáveis (Dias Sobrinho, 2005).

Do exposto, esperamos ter esclarecido a concepção que a RCT tem como fundamento para proceder à materialização do processo formativo que realiza, operacionalizado conforme explicitado no próximo tópico.

\section{Operacionalização do processo de gestão, avaliação, monitoramento e acompanhamento da RCT}

Avaliação, monitoramento e acompanhamento têm uma estreita relação, mas não se confundem nos aspectos teórico-práticos. A avaliação, em seu sentido genérico, relaciona-se à ideia de aprimorar, aprender e julgar. 
Depreendemos do exposto anteriormente que as perspectivas de avaliações são disputadas pelas forças políticas, econômicas, científicas e sociais em busca da formação de uma dada hegemonia.

A perspectiva hegemônica de avaliação, na sociedade capitalista do século XXI, continua sendo aquela que privilegia o monitoramento como recorte das avaliações em função do aprimoramento gerencial dos resultados, principalmente ajustando com rigor os objetivos às metas planejadas.

Sem desconsiderar a importância do monitoramento na coleta de dados, o vínculo orgânico que a proposta da RCT apresenta é entre avaliação, na perspectiva democrático-participativa,

e acompanhamento das práticas sociais, traduzidas em relações educativas, tendo como preocupação a valorização de mais diálogo e menos instrumentos ou meios utilizados para tal prática. Com isso, estamos dizendo que o mais importante são as relações sociais que se estabelecem no processo formativo da RCT como práxis educativa que submete os critérios instrumentais aos critérios substantivos da formação.

Perspectivas, dimensões e critérios do processo de gestão, avaliação, monitoramento e acompanhamento da RCT
O monitoramento,

0 acompanhamento e a avaliação, no âmbito da RCT, considera, em uma visão ampla, a articulação das perspectivas instrumental e substantiva no processo formativo municipal (Sander, 1995).

Em relação à perspectiva instrumental do processo formativo, relacionamos as dimensões econômica e tecno-administrativa e pedagógica. $\mathrm{O}$ critério orientador da dimensão econômica e tecno-administrativa é a eficiência relacionada à lógica racional e utilitária, a qual visa ao preparo técnico competente de seus profissionais e à maximização da captação e da utilização de seus recursos financeiros e tecnológicos. Tem a ver, nesse sentido, com o controle dos resultados quantitativos, indicadores de eficiência que conjugam a produção, em geral, e educacional, em particular, realizada em menor tempo, com menos recursos e que cumpra uma meta máxima de $100 \%$, ou próximo disso, em relação ao que foi planejado.

A dimensão pedagógica, considerando o processo educativo ampliado, atribui à gestão do processo educativo a função de coordenar a criação e utilização de cenários, conteúdos, espaços, métodos e técnicas, em busca do alcance dos fins e objetivos da educação para cumprir, para além do papel 
econômico, principalmente o político e o cultural. Essa dimensão está comprometida com o alcance dos objetivos do sistema educacional e dos processos formativos em geral, expresso no critério de eficácia formativa.

No tocante à perspectiva substantiva do processo formativo, relacionamos as dimensões política e cultural. A dimensão política possui estreita conexão com o contexto pedagógico, econômico e cultural, no qual o processo formativo ocorre. Sem desconsiderar os múltiplos determinantes que interferem na realização da ação pedagógica, prima pelo exercício efetivo de sua função social, voltada ao atendimento das necessidades e demandas de seus agentes sociais em formação. A efetividade é o critério fundante dessa dimensão formativa, ou seja, ela prima por uma efetiva participação nas tomadas de decisão no âmbito das instituições educativas com repercussões para a ação dos sujeitos sociais em processo de formação na vida social nacional e local.

Implicada na dimensão anterior e articulada a ela, destaca-se a dimensão cultural - relacionada ao critério da relevância - que tem como pressuposto básico a visão totalizante da realidade historicamente construída pelo conjunto dos homens em sociedade. Com esse entendimento, a educação está comprometida com as práticas sociais das pessoas e dos grupos que participam direta ou indiretamente do processo educacional, objetivando estabelecer condições materiais e imateriais que permitam a plena realização do ser humano como sujeito, buscando agregar sentido e significado valorativo à formação humana, por meio, também, dos diversos processos educativos.

As perspectivas e dimensões formativas aventadas, no entendimento aqui adotado, têm o propósito de superar as posturas individualistas e funcionalistas, usualmente desenvolvidas nos processos formativos em geral. Tais posturas - em contraposição com a perspectiva de uma formação omnilateral (Gramsci, 2000) desvinculam os diversos níveis ou dimensões da realidade global como se estes existissem de forma autônoma. Por essa linha de raciocínio, a educação, em sentido omnilateral, tem papel mediador, no sentido de articular dialeticamente as dimensões econômica, pedagógica, efetiva e relevante (Carvalho, 2016). Nessa lógica, “a eficiência é subsumida pela eficácia; a eficácia e a eficiência são subsumidas pela efetividade; e a efetividade, a eficácia e a eficiência são subsumidas pela relevância" (Sander, 1995, p. 67). Ocorre, portanto, o resgate do valor correto das dimensões no processo de gestão, acompanhamento e 
avaliação, dando uma unicidade formativa

em busca da desalienação da

desfragmentação e afirmação da

autonomia, propósito caro ao projeto da

RCT.

No quadro seguinte, sintetizamos as perspectivas e dimensões formativas discutidas anteriormente e explicitamos os indicadores e as evidências que a RCT utiliza como norteamento geral do processo de gestão, acompanhamento e avaliação do projeto formativo em desenvolvimento junto aos municípios.

Quadro 3 - Indicadores/evidências e critérios do processo de gestão, avaliação, monitoramento e acompanhamento da RCT.

\begin{tabular}{|c|c|c|}
\hline $\begin{array}{l}\text { PERSPECTIVAS } \\
\text { FORMATIVAS }\end{array}$ & CRITÉRIOS & $\begin{array}{c}\text { INDICADORES/ } \\
\text { EVIDÊNCIAS RCT }\end{array}$ \\
\hline \multirow[b]{2}{*}{ Instrumental } & Eficiência & $\begin{array}{l}\text { 1) Valor de recursos financeiros investidos; } \\
\text { 2) Número de profissionais envolvidos; } \\
\text { 3) Número de eventos realizados; } \\
\text { 4) Número de municípios atendidos; } \\
\text { 5) Número de cursistas formados } \\
\text { 6) etc. }\end{array}$ \\
\hline & Eficácia & $\begin{array}{l}\text { 1) Planejamento realizado; } \\
\text { 2) Materiais didáticos produzidos; } \\
\text { 3) Formações realizadas; } \\
\text { 4) Avaliações realizadas; } \\
\text { 5) Relatórios produzidos; } \\
\text { 6) Objetivos alcançados quanto à aprendizagem dos } \\
\text { objetos propostos no projeto } \\
\text { 7) etc. }\end{array}$ \\
\hline \multirow{2}{*}{ Substantiva } & Efetividade & $\begin{array}{l}\text { 1) Repercussão do curso na participação dos cursistas em } \\
\text { relação à sua prática: } \\
\text { a) no curso realizado pela RCT; } \\
\text { b) na gestão do sistema municipal; } \\
\text { c) na gestão das escolas; } \\
\text { d) na gestão do processo de ensino e aprendizagem; } \\
\text { e) no âmbito municipal } \\
\text { f) etc. }\end{array}$ \\
\hline & Relevância & $\begin{array}{l}\text { 1) Repercussão do curso na mudança dos valores dos } \\
\text { cursistas em relação à sua prática: } \\
\text { a) no curso realizado pela RCT; } \\
\text { b) na gestão do sistema municipal; } \\
\text { c) na gestão das escolas; } \\
\text { d) na gestão do processo de ensino e aprendizagem; } \\
\text { e) no âmbito municipal } \\
\text { f) etc. }\end{array}$ \\
\hline \multicolumn{3}{|l|}{ OBSERVAÇÕES: } \\
\hline
\end{tabular}

Fonte: elaboração dos autores com base em Sander (1995); Carvalho (2016).

processo de gestão, avaliação,

Tomando como referência o quadro monitoramento e acompanhamento da anterior, que explicita, em geral, os RCT, detalhamos, a seguir, parâmetros indicadores/evidências e critérios do norteadores para a gestão, 
tocante a blocos, objetivos, indicadores,

Quadro 4 - Parâmetros norteadores para a gestão, a avaliação, o monitoramento e o acompanhamento da RCT: blocos, objetivos, indicadores, medida e período.

OBJETIVO GERAL - Apoiar as redes e os sistemas municipais de educação/ensino do Estado do Tocantins no enfrentamento da crise educacional derivada da pandemia da COVID-19, notadamente na sistematização da oferta educacional no período da pandemia e no processo de retomada das atividades educacionais.

\begin{tabular}{|c|c|c|c|c|c|}
\hline RCT & & Objetivo & Indicador & Medida & Período \\
\hline \multirow[t]{7}{*}{ Bloco I } & 1 & $\begin{array}{c}\text { Realizar, em } \\
\text { colaboração com órgãos } \\
\text { de controle externo } \\
\text { presentes no Tocantins, } \\
\text { diagnóstico das redes e } \\
\text { dos sistemas municipais } \\
\text { de educação/ensino. }\end{array}$ & 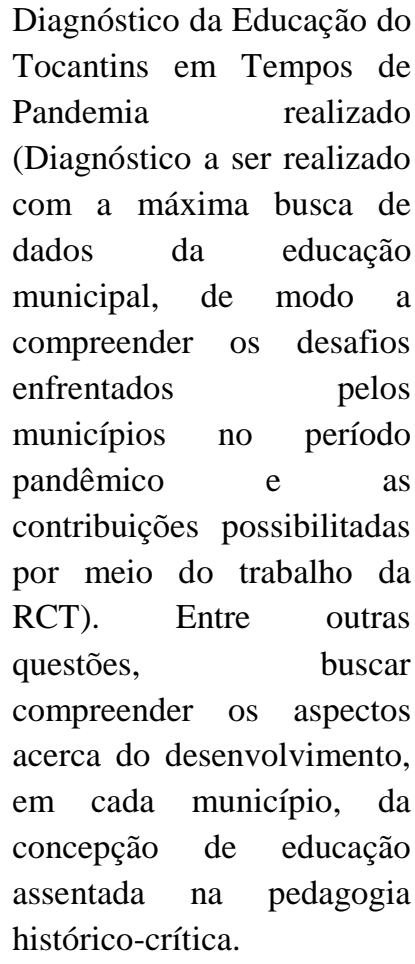 & Série histórica & semestral \\
\hline & \multirow{3}{*}{2} & \multirow{3}{*}{$\begin{array}{l}\text { Elaborar material para a } \\
\text { formação de dirigentes, } \\
\text { técnicos e diretores } \\
\text { escolares. }\end{array}$} & $\begin{array}{lr}\text { Tipos e } & \text { quantidade de } \\
\text { material } & \text { formativo } \\
\text { elaborados. } & \end{array}$ & $\begin{array}{l}\text { A cada módulo de } \\
\text { formação }\end{array}$ & \multirow{3}{*}{ bimestral } \\
\hline & & & $\begin{array}{l}\text { Município com trabalho } \\
\text { efetivado com o apoio do } \\
\text { material produzido. }\end{array}$ & $\begin{array}{l}\text { A cada módulo de } \\
\text { formação }\end{array}$ & \\
\hline & & & $\begin{array}{l}\text { Contribuições do material } \\
\text { produzido para a promoção } \\
\text { da concepção da pedagogia } \\
\text { histórico-crítica. }\end{array}$ & $\begin{array}{l}\text { Conhecida a cada } \\
\text { avaliação do } \\
\text { módulo }\end{array}$ & \\
\hline & \multirow{3}{*}{3} & \multirow{3}{*}{$\begin{array}{c}\text { Proporcionar para a } \\
\text { equipe gestora formação } \\
\text { voltada para o } \\
\text { enfrentamento da crise } \\
\text { educacional }\end{array}$} & $\begin{array}{l}\text { Formação desenvolvida } \\
\text { com equipe gestora voltada } \\
\text { para o enfrentamento da } \\
\text { crise educacional. }\end{array}$ & $\begin{array}{l}\text { Número de } \\
\text { formações } \\
\text { realizadas }\end{array}$ & semestral \\
\hline & & & $\begin{array}{l}\text { Município com trabalho } \\
\text { efetivado com o apoio das } \\
\text { formações desenvolvidas. }\end{array}$ & $\begin{array}{l}\text { Conhecimento por } \\
\text { meio de } \\
\text { acompanhamento } \\
\text { e avaliação }\end{array}$ & bimestral \\
\hline & & & $\begin{array}{l}\text { Contribuição da formação } \\
\text { para a promoção da }\end{array}$ & $\begin{array}{c}\text { Conhecimento por } \\
\text { meio de }\end{array}$ & Contínuo \\
\hline
\end{tabular}




\begin{tabular}{|c|c|c|c|c|c|}
\hline & & & $\begin{array}{l}\text { concepção da pedagogia } \\
\text { histórico-crítica. }\end{array}$ & $\begin{array}{l}\text { acompanhamento } \\
\text { e avaliação }\end{array}$ & \\
\hline \multirow{5}{*}{ Bloco II } & \multirow{3}{*}{4} & \multirow{3}{*}{$\begin{array}{c}\text { Disponibilizar rede de } \\
\text { apoio e suporte técnico } \\
\text { aos sistemas e às redes } \\
\text { municipais de } \\
\text { educação/ensino para o } \\
\text { enfrentamento da crise } \\
\text { educacional. }\end{array}$} & $\begin{array}{l}\text { Rede de apoio e suporte } \\
\text { técnico disponibilizados aos } \\
\text { municípios. }\end{array}$ & $\begin{array}{c}\text { Formas } \\
\text { desenvolvidas de } \\
\text { apoio aos } \\
\text { municípios } \\
\text { (WhatsApp, } \\
\text { email...) }\end{array}$ & \\
\hline & & & $\begin{array}{l}\text { Satisfação dos municípios } \\
\text { em relação ao apoio e ao } \\
\text { suporte } \\
\text { disponibilizados }\end{array}$ & $\begin{array}{l}\text { Conhecimento por } \\
\text { meio do } \\
\text { acompanhamento } \\
\text { e das avaliações } \\
\text { do módulo }\end{array}$ & \\
\hline & & & $\begin{array}{l}\text { Contribuição do apoio e do } \\
\text { suporte técnico para a } \\
\text { promoção da concepção da } \\
\text { pedagogia histórico-crítica. }\end{array}$ & $\begin{array}{l}\text { Conhecimento por } \\
\text { meio do } \\
\text { acompanhamento } \\
\text { e das avaliações } \\
\text { do módulo }\end{array}$ & \\
\hline & 5 & $\begin{array}{l}\text { Acompanhar e avaliar as } \\
\text { ações propostas pelas } \\
\text { redes e pelos sistemas } \\
\text { municipais de } \\
\text { educação/ensino. } \\
\end{array}$ & $\begin{array}{l}\text { Verificação de cumprimento } \\
\text { dos objetivos formativos } \\
\text { dos blocos I e III. }\end{array}$ & $\begin{array}{l}\text { Elaboração de } \\
\text { relatórios parciais } \\
\text { e final sobre o } \\
\text { resultado } \\
\text { formativo } \\
\end{array}$ & semestral \\
\hline & 6 & $\begin{array}{c}\text { Publicar material } \\
\text { científico com registro } \\
\text { analítico da proposta (da } \\
\text { RCT?) }\end{array}$ & 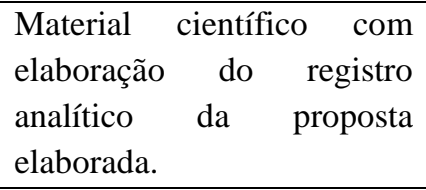 & $\begin{array}{l}\text { Quantidade de } \\
\text { material produzido }\end{array}$ & anual \\
\hline \multirow{4}{*}{ Bloco III } & \multirow{3}{*}{7} & \multirow{3}{*}{$\begin{array}{c}\text { Proporcionar para os } \\
\text { professores e } \\
\text { coordenadores } \\
\text { pedagógicos formação } \\
\text { voltada para os desafios } \\
\text { da crise educacional. }\end{array}$} & $\begin{array}{l}\text { Formação para os } \\
\text { professores e coordenadores } \\
\text { pedagógicos voltada para os } \\
\text { desafios existentes da crise } \\
\text { educacional. }\end{array}$ & $\begin{array}{l}\text { Número de } \\
\text { formações } \\
\text { realizadas. Por } \\
\text { módulo }\end{array}$ & \multirow{4}{*}{ semestral } \\
\hline & & & $\begin{array}{l}\text { Município com trabalho } \\
\text { efetivado com o apoio das } \\
\text { formações desenvolvidas. }\end{array}$ & $\begin{array}{l}\text { Conhecimento por } \\
\text { meio do } \\
\text { diagnóstico ou das } \\
\text { avaliações do } \\
\text { módulo }\end{array}$ & \\
\hline & & & $\begin{array}{l}\text { Contribuição da formação } \\
\text { para a promoção da } \\
\text { concepção da pedagogia } \\
\text { histórico-crítica. }\end{array}$ & $\begin{array}{l}\text { Conhecimento por } \\
\text { meio do } \\
\text { diagnóstico ou das } \\
\text { avaliações do } \\
\text { módulo } \\
\end{array}$ & \\
\hline & 8 & $\begin{array}{c}\text { Elaborar material para a } \\
\text { formação de } \\
\text { professores. }\end{array}$ & $\begin{array}{l}\text { Material elaborado para a } \\
\text { formação de professores. }\end{array}$ & $\begin{array}{l}\text { Quantidade de } \\
\text { material elaborado }\end{array}$ & \\
\hline \multirow[b]{2}{*}{$\begin{array}{l}\text { Blocos I, } \\
\text { II e III }\end{array}$} & \multirow[b]{2}{*}{9} & \multirow{2}{*}{$\begin{array}{l}\text { Realizar Seminário da } \\
\text { Superação da Crise com } \\
\text { a participação de } \\
\text { palestrantes estaduais e } \\
\text { nacionais, vinculados ao } \\
\text { campo democrático } \\
\text { popular/progressista; }\end{array}$} & $\begin{array}{l}\text { Seminário da Superação da } \\
\text { Crise realizado }\end{array}$ & Evento realizado & anual \\
\hline & & & $\begin{array}{l}\text { Trabalhos diversificados } \\
\text { (resumos/ artigos/ relatos de } \\
\text { experiência) e avaliação das } \\
\text { ações realizadas pelas redes }\end{array}$ & $\begin{array}{c}\text { Trabalhos } \\
\text { apresentados. } \\
\text { Ações } \\
\text { desenvolvidas }\end{array}$ & Contínuo \\
\hline
\end{tabular}




\begin{tabular}{|l|l|l|l|l|}
\hline & $\begin{array}{l}\text { apresentação de } \\
\text { trabalhos e avaliação das }\end{array}$ & e pelos sistemas municipais \\
ações realizadas pelas & apresentadas no seminário. \\
redes e pelos sistemas & & \\
municipais & de \\
educação/ensino. & & \\
\hline
\end{tabular}

Fonte: elaboração dos autores com base no processo formativo realizado pela RCT (2020a; 2020b; 2021).

Tomando por referência os quadros anteriores, para concluir a proposta de acompanhamento e de avaliação, ressaltase a necessidade de definição de um instrumento padrão de sintetização dos dados coletados no decorrer do processo de formação da RCT, nos termos descritos para a elaboração dos quadros de indicadores e de parâmetros.

A visão apresentada, tanto no aspecto estratégico-empresarial como na avaliação democrático-participativa, expõe apenas diretrizes delineadas na elaboração do projeto de trabalho, já que todo o detalhamento das ações é desenvolvido pelos blocos formativos a partir da realidade objetiva e da operacionalização de cada ação.

\section{Diante disso, quanto ao Quadro de} indicadores de critérios: na perspectiva formativa instrumental faz-se necessário elaborar o quadro com critérios para observação e registros de dados; por outro lado, na perspectiva formativa substantiva enfatiza-se a importância de desenvolver planejamento e relatórios das formações etapa municipal, elaborar quadro e critérios para observação do material recebido; formulário ou quadro para coleta de dados das avaliações dos cursistas em relação à formação do encontro síncrono etapa RCT e etapa municipal..

No que se refere ao Quadro indicadores de parâmetros: Bloco I Diagnóstico - deve-se destacar a revisão do questionário já aplicado para possíveis substituições e inserção de itens e reaplicação do instrumento, bem como, o quadro com critérios de observação do material elaborado/planejamento, relatórios e avaliações referentes a cada módulo de formação; Bloco II: apoio e suporte pesquisa de satisfação ou questionário de avaliação sobre a percepção das equipes municipais quanto ao apoio realizado e aos canais utilizados; quadro com critérios de observação e coleta de dados das avaliações e do alcance dos objetivos propostos. Bloco III: quadro com critérios de observação quanto ao material elaborado para formações, observação e coleta de informações a partir das avaliações dos cursistas da etapa RCT e da etapa municipal das formações e do seminário 
(planejamento/execução/produções percepção dos participantes).

A gestão, a avaliação, o monitoramento e o acompanhamento ocorrerão a partir da articulação entre as duas etapas: RCT/Especialistas e Municipal, tendo em vista que a formação síncrona e a atividade assíncrona devem tomar como referência o campo da ação e visam ao apoio em tempo real aos municípios.

Em relação à etapa/patamar RCT/especialistas, o acompanhamento e a avaliação ocorrerão por meio da coleta, do acompanhamento e da análise dos indicadores e critérios do processo de gestão, evidenciados nos relatórios a serem produzidos pelos coordenadores ou formadores que compõem os blocos I e III, em atendimento aos critérios descritos para as perspectivas formativa instrumental e substantiva, descritas no Quadro 3; ao objetivo geral que justifica a existência da RCT, assim como aos objetivos de cada Bloco que a compõe; às ações de diagnóstico das redes e dos sistemas de ensino, da formação para equipes gestoras e pedagógicas, do acompanhamento e da avaliação dos indicadores propostos para evidenciar o alcance dos objetivos apresentados, por meio das ações desenvolvidas e dos relatórios produzidos, a partir dos instrumentos de medida propostos para cada ação, conforme o Quadro 4.

No tocante ao patamar/etapa municipal, o acompanhamento e a avaliação ocorrerão por meio da organização e entrega de dados e relatórios solicitados, que englobam desde o processo de inscrição dos cursistas, a participação, o envolvimento nas ações e atividades propostas, até uma avaliação, com abrangência de itens definidos pelas equipes de formação municipal, que comprovem a efetivação da formação, levando em consideração a relação entre teoria e prática, a organização, a análise e a publicização dos resultados do processo de acompanhamento e de avaliação da RCT, considerando o processo formativo em movimento.

Nesse sentido, a organização dos dados será realizada pelos formadores que compõem os blocos I e III, mediante relatórios apresentados após cada etapa de formação, com critérios estabelecidos para o planejamento e para a operacionalização das formações ocorridas nos momentos síncronos e para a organização e entrega de produtos e/ou relatórios das atividades assíncronas já definidas em cada etapa da formação a ser realizada.

A organização, o arquivamento, a guarda e a análise dos dados ocorrem continuamente pelos profissionais que 
compõem o bloco II, com a finalidade de evidenciar riscos e fragilidades, bem como induzir à correção célere do processo, conforme a formação nas redes e nos sistemas de ensino forem ocorrendo, durante as ações de planejamento, realização de encontros síncronos e realização de atividades assíncronas.

A análise dos dados e resultados do processo de acompanhamento e avaliação das ações ocorrerá no âmbito da RCT e dos Municípios, a cada bimestre. A publicização geral dos dados analisados e das ações desenvolvidas ocorrerá mediante a realização de um seminário com a participação de palestrantes estaduais e nacionais, vinculados ao campo democrático popular/progressista, com a apresentação de trabalhos pelos representantes das redes e dos sistemas e com a avaliação das ações realizadas. Nesse Seminário, será apresentada proposta da publicação de uma Coletânea de artigos científicos e relatos de experiência relacionados ao desenvolvimento da proposta.

Buscando coletar e publicizar as experiências relevantes do processo formativo, a Comissão de Gestão se responsabilizará pela elaboração de instrumentos e/ou de um aplicativo, e a RCT, em parceria com a União dos Dirigentes Municipais de Educação
(UNDIME-TO) disponibilizará uma plataforma digital, para que os municípios a alimentem com as experiências inovadoras de gestão e pedagógicas, para que fiquem acessíveis às demais redes e aos sistemas.

\section{Considerações finais}

A pesquisa permitiu problematizar a concepção instrumental de educação e de avaliação por meio de reflexão teóricofilosófica, contrapondo-a à concepção que entende a educação como práxis social calcada nos princípios da gestão democrática e da formação substantiva, sendo, ambas, representativas de projetos de educação em disputa.

$\mathrm{Na}$ arena dessa disputa, avaliação, monitoramento e acompanhamento seguem cursos distintos e relacionam-se, em grande medida, à concepção de educação, à forma de gestão em geral e ao ideário de regulação adotado, podendo ser caracterizados como funcionalista enraizada nas teorias positivistas e evolucionista - e, interacionista, com mediação reflexiva das diferenças sociais numa perspectiva materialista e críticodialética.

Da problematização, apontamos o caráter emancipador, democrático e a valorização dos sujeitos em processo educativo como a perspectiva escolhida 
pela RCT como fundamento para proceder à materialização do processo formativo que realiza.

Tal perspectiva, a partir dos quadros apresentados, perpassam os processos de gestão, avaliação, monitoramento e acompanhamento, com formações síncronas e atividades assíncronas que tomam como referência o campo da ação com apoio em tempo real aos municípios, de modo que o processo avaliativo seja contemplado com análise dos dados e dos resultados do processo publicizados bimestralmente e mediante a realização de seminários e atividades diversificadas como: socialização de trabalhos, rodas de conversa e debates.

Assim, a perspectiva da RCT desenvolve-se no campo da ação das redes e dos sistemas e, por meio do processo formativo do qual a própria avaliação faz parte, volta-se ao campo da ação de forma mais elaborada e transformada, a partir de uma qualidade socialmente referenciada.

O percurso metodológico possibilitou realizarmos uma reflexão teórico-filosófica acerca da avaliação, do monitoramento e do acompanhamento identificando perspectivas antagônicas. A reflexão em pauta fundamentou a prática formativa entendida como práxis articuladora da ação-reflexão-ação tendo a educação municipal como ponto de partida.

Posto isto, é possível indicar que a formação realizada pela RCT, especialmente o monitoramento, o acompanhamento e a avaliação, caracteriza-se como práticas substantivas e inovadoras - por ser emancipador, democrático e propor valorização dos sujeitos -, contribuindo assim para o conhecimento da área.

\section{Referências}

Carvalho, R. F. (2011). O processo de gestão e participação na universidade: limites, desafios e possibilidades na UFT (Tese de Doutorado). Universidade Federal de Goiás, Goiânia.

Carvalho, R. F. (2016). A constituição do Estado brasileiro na tensão entre o domínio e a direção de classe: a educação como arena ético-política. In Vilas Bôas, J. P. S., Neto, L. F., \& Perius, O. (Orgs.). Filosofia em Debate: questões de ética, educação e política (pp. 297-240). Florianópolis: Nefiponline.

Chauí, M. S. (1980). Ideologia e educação. Educação e Sociedade. São Paulo: Cortez/CEDES.

Chauí, M. S. (1999, 9 de maio). A Universidade Operacional. Folha de São Paulo, caderno mais (5), 3.

Contera, C. (2002). Modelos de avaliação da qualidade da educação superior. In Dias Sobrinho, J., Ristoff, D. I. (Org.). Avaliação de democrática: para uma universidade cidadã (pp. 119-144). Florianópolis: Insular. 
Dias Sobrinho, J. (2003). Avaliação: políticas educacionais e reformas da educação superior. São Paulo: Cortez.

Dias Sobrinho, J. (2005). Avaliação como instrumento da formação cidadã e do desenvolvimento da sociedade democrática: por uma ético-epistemologia da avaliação. In Ristoff, D., \& Almeida Júnior, V. P. (Orgs.). Avaliação participativa: perspectivas e desafios (pp. 15-38). Brasília: Inep.

Dias Sobrinho, J., \& Ristoff, D. I. (Orgs.). (2002). Avaliação de democrática: para uma universidade cidadã. Florianópolis: Insular.

Gramsci, A. (2000). Cadernos do Cárcere. Rio de Janeiro: Civilização Brasileira.

RCT/TO. (2020a). Caderno I. Gestão da Educação: validação das ações administrativas e pedagógico-curriculares e finalização do ano letivo de 2020. Palmas/TO, Undime.

RCT/TO. (2020b). Caderno 2. Gestão da educação na conjuntura da pandemia Com a palavra, cursistas e formadores. Palmas/TO, Undime.

RCT/TO. (2021). Caderno 3. Gestão das redes e dos sistemas educacionais: afirmação dos direitos à vida e a educação no retorno às atividades escolares em 2021. Palmas/TO, Undime.

Sander, B. (1995). Gestão da educação na América Latina: construção e reconstrução do conhecimento. Campinas: Autores Associados.
Publicado em: 19/12/2021

Received on November 29th, 2021

Accepted on December 04th, 2021

Published on December, 19th, 2021

Contribuições no Artigo: Os(as) autores(as) foram os(as) responsáveis por todas as etapas e resultados da pesquisa, a saber: elaboração, análise e interpretação dos dados; escrita e revisão do conteúdo do manuscrito e; aprovação da versão final publicada.

Author Contributions: The author were responsible for the designing, delineating, analyzing and interpreting the data, production of the manuscript, critical revision of the content and approval of the final version published.

Conflitos de Interesse: Os(as) autores(as) declararam não haver nenhum conflito de interesse referente a este artigo.

Conflict of Interest: None reported.

Avaliação do artigo

Artigo avaliado por pares.

Article Peer Review

Double review.

Agência de Fomento

Não tem.

Funding

No funding.

Como citar este artigo / How to cite this article

APA

Brito, K. C. C. F., Sousa, A. R., \& Carvalho, R. F. (2021). Avaliação, monitoramento e acompanhamento do processo formativo na RCT: aspectos teórico-práticos e operacionais. Rev. Bras. Educ. Camp., 6, e13296. http://dx.doi.org/10.20873/uft.rbec.e13296

\section{ABNT}

BRITO, K. C. C. F.; SOUSA, A. R.; CARVALHO, R. F. Avaliação, monitoramento e acompanhamento do processo formativo na RCT: aspectos teórico-práticos e operacionais. Rev. Bras. Educ. Camp., Tocantinópolis, v. $6, \quad$ e13296 2021. http://dx.doi.org/10.20873/uft.rbec.e13296 